\title{
Twentieth century forest-grassland ecotone shift in Montana under differing livestock grazing pressure
}

\author{
Temuulen Tsagaan Sankey*, Cliff Montagne, Lisa Graumlich, Rick Lawrence, Jerry Nielsen \\ Land Resources and Environmental Sciences Department, Montana State University, Bozeman, MT 59717, USA \\ Received 18 April 2006; received in revised form 12 July 2006; accepted 12 July 2006
}

\begin{abstract}
We studied 20th century lower forest-grassland ecotone shift in the Centennial Valley in southwestern Montana and investigated the effects of livestock herbivory on ecotone shift at a local spatial scale and a decadal time scale. A total of 525 aspen (Populus tremuloides) and 1703 Douglasfir (Pseudotsuga menziesii) trees were cored and 10,168 saplings were mapped along the ecotone at five sites that represented five different grazing regimes. Tree-age distribution was constructed to determine 20th century tree establishment. Tree age and location within the ecotone were correlated to describe the process of ecotone shift into the adjacent grassland. To corroborate the dendrochronological data and to detect changes in the ecotone, historic and current aerial photographs were compared. To examine livestock herbivory effects on ecotone shift at a decadal time scale, the number of new trees was correlated with 10 different levels of cattle grazing pressure during the last 60 years.

Two different types of ecotone shift were documented. Previously documented simple linear relationships between livestock herbivory and tree encroachment were not consistently observed at decadal time scales. Livestock herbivory had a complex relationship with tree encroachment. Our results suggested that no consistent conclusions could be made regarding grazing effects on tree establishment across broad ranges of grazing pressure at decadal time scales. We suggest that the way forward needs to use a process-based approach to devise strategies for observing and quantifying multiple interacting processes of inhibition and facilitation effects.
\end{abstract}

(C) 2006 Elsevier B.V. All rights reserved.

Keywords: Ecotone shift; Livestock herbivory; Aspen; Douglas-fir

\section{Introduction}

\subsection{Forest-grassland ecotone shift}

Forest-grassland ecotone shift has been observed in many different parts of the world and is attracting greater attention due to its implications for global carbon sequestration and land surface-atmosphere interactions (Archer, 1999; Mather, 2000). Woody species encroachment into grasslands has been correlated with climate change, increased $\mathrm{CO}_{2}$, fire suppression, herbivory, and snow accumulation (Dando and Hansen, 1990; Kupfer and Cairns, 1996; Bachelet et al., 2000; Bartolome et al., 2000). The effects of these factors are more commonly studied at alpine treeline than at lower forestgrassland ecotones.

\footnotetext{
* Corresponding author at: GIS Center, Idaho State University, Building 15, Graveley Hall B-20, Campus Box 8130, Pocatello, ID 83209-8130, USA. Tel.: +1 208282 3606; fax: +1 2082825802 .

E-mail address: sankteki@isu.edu (T.T. Sankey).
}

We studied a lower forest-grassland ecotone shift in the Centennial Valley in southwestern Montana, USA and investigated two types of ecotone change using dendrochronological data and aerial photographs: (1) a shift in forestgrassland boundary location towards the adjacent grassland and (2) an increase in tree density at the forest-grassland boundary beneath the forest canopy (Arno and Gruell, 1986). We examined ecotone shift under different levels of livestock grazing pressure using non-experimental observational grazing data of the last 60 years to determine if conclusions from previous grazing studies were consistent with patterns observed at decadal time scales. Determining possible causes of lower forest-grassland ecotone shift at a regional scale was not our objective. We, therefore, did not correlate potential causes such as increased $\mathrm{CO}_{2}$, climate change, and fire suppression with ecotone shift in the Centennial Valley.

Our objectives were (1) to determine if lower forestgrassland ecotone shift occurred in the Centennial Valley during the 20th century, and (2) to examine the effects of livestock herbivory on ecotone shift at a local scale, if ecotone shift had occurred. Four questions were of primary interest: (1) 
Is the lower forest-grassland ecotone shifting and is ecotone tree density increasing? (2) If so, do different levels of grazing pressure lead to different rates of ecotone shift? (3) Within the same level of grazing pressure, do different tree species respond to grazing differently? (4) Do the decadal scale trends in tree encroachment, if any, consistently show a simple linear increase or decrease as grazing levels increase? We also considered the effects of topographic variables on ecotone shift.

\subsection{Grazing effects on ecotone shift}

Woody species encroachment due to grazing in North America has been observed in arid and semi-arid regions of western and southwestern USA (Archer, 1999). Studies from this region suggest that grazing facilitates woody species encroachment (Archer, 1999). We might, therefore, expect increasing woody species encroachment with increasing grazing intensity. However, the opposite effects of grazing on woody species encroachment have also been demonstrated (Carmel and Kadmon, 1999; Bartolome et al., 2000). Such studies suggest that grazing can inhibit tree seedling establishment, survival, and growth. We might, therefore, expect decreasing woody species encroachment into grasslands with increasing grazing intensity based on this conclusion.

Lower forest-grassland ecotone shift requires a sequence of events: tree seed dispersal into the adjacent grassland, germination of seeds, emergence, growth, survival, and recruitment of seedlings into the tree population (Hill et al., 1995). Each of these processes can be impacted by herbivory, an important local control over vegetation. Ecological processes of positive net effects of grazing on woody species have been summarized by Archer (1999). They include: (1) grazing decreases seed production, seedling establishment, biomass, and basal area of palatable herbaceous species and increases their mortality; (2) reduced herbaceous species ground cover increases sunlight levels on the ground, which increases seed germination and early establishment of woody species seedlings; (3) reduced herbaceous species biomass decreases fine fuel accumulation and reduces fire frequency, which increases woody species invasion; (4) invading woody species are less palatable than herbaceous species and are not browsed enough to be eliminated; (5) grazing makes herbaceous species less able to compete for resources and unable to limit woody species growth and their seedling establishment; (6) livestock disperse woody species seeds across the landscape.

Negative effects of grazing on woody species, especially palatable species such as aspen, have also been widely documented. They include: (1) slow growth rate of most woody species allows repeated grazing in their seedling stage when they are most vulnerable to grazing (Alverson et al., 1988; Tilghman, 1989); (2) intense grazing causes shoot loss, tissue damage, and biomass loss for woody species (Hjalten et al., 1993), such as aspen (Kay and Bartos, 2000; Kilpatrick and Abendroth, 2001; Rumble et al., 1996; Smith et al., 1972; Singer, 1996); (3) these losses decrease their seedling growth (Alverson et al., 1988; Tilghman, 1989) and increase seedling mortality (Hjalten et al., 1993); (4) increased seedling mortality reduces recruitment into the tree population (McInnes et al., 1992; Rooney et al., 2002); (5) trampling and rubbing against aspen bark by grazing animals damage trees and their seedlings (Kay and Bartos, 2000).

The current literature illustrates two seemingly conflicting grazing impacts on woody species. All grazing impact studies demonstrate one or the other of these two conflicting effects, but none demonstrates both. At decadal time scales, we might expect, based on these conclusions, a simple linear increase in tree encroachment or a simple linear decrease in tree encroachment with increasing grazing levels. We explored the relationship between tree encroachment and livestock herbivory effects at decadal time scales to determine (1) if only facilitation effect or inhibition effect is observed at decadal time scales and (2) if the trend is consistent across different grazing gradients and two different tree species.

We studied a single, $15 \mathrm{~km}$ long lower forest-grassland ecotone and examined tree regeneration and recruitment patterns as impacted by different levels of cattle grazing pressure along three gradients: (1) a gradient of five relatively lower levels of grazing pressure; (2) a gradient of five relatively higher levels of grazing pressure; (3) a gradient across all 10 levels of grazing pressure. Our gradients of grazing pressure were constructed based on long-term observational data of stocking rates (estimated in animal unit months per hectare (AUM/ha)) at each site. We assigned a category to each level of grazing pressure at each site. The categories do not represent evenly distributed levels of grazing pressure along the gradients (Table 1). Further, the third gradient does not combine the two smaller gradients sequentially, and the order of the grazing levels thus changes from the smaller gradients to the broader gradient. We were unable to control other potential factors that influence tree regeneration and recruitment due to the temporal and spatial extent of our study. We were also unable to control and estimate long-term variation in grazing use within each site and assumed even distribution throughout each site as they each represented a single grazing allotment.

Table 1

Historic and current averages of grazing pressure estimated in AUM/ha at the five sites

\begin{tabular}{ll}
\hline Grazing levels & AUM/ha \\
\hline Current grazing level 1* $^{*}$ & 0.00 \\
Current grazing level 2* $^{*}$ & 0.11 \\
Current grazing level 3* $^{*}$ & 0.17 \\
Current grazing level 4* $^{*}$ & 0.79 \\
Current grazing level 5* & 1.00 \\
Historic grazing level 1 & 0.12 \\
Historic grazing level 2 & 0.28 \\
Historic grazing level 3 & 0.41 \\
Historic grazing level 4 & 0.50 \\
Historic grazing level 5 & 2.00
\end{tabular}

Current grazing levels provided a gradient of five lower grazing levels, while the historic grazing levels provided a gradient of five higher grazing levels. Grazing levels were ranked in the order from the lowest to the highest level within each gradient. The grazing levels from these two gradients were combined to create a third gradient with a broader range of grazing levels ranging from the minimum grazing level to the maximum grazing level from the two smaller gradients. The order is, therefore, different along the third gradient. 


\subsection{Difference in tree species response to grazing}

Douglas-fir (Pseudotsuga menziesii) and aspen (Populus tremuloides) are the dominant tree species along the lower forest-grassland ecotone in the Centennial Valley. Aspen is considered to be a seral species in the Centennial Range, while Douglas-fir is a climax species (Mueggler, 1988). Aspen is a deciduous species that regenerates clonally (DeByle and Winokur, 1985). Douglas-fir is a coniferous species that reproduces through seeds (Hermann and Lavender, 1965). Aspen and Douglas-fir are expected to respond to herbivory differently due to their differences in palatability and tolerance to grazing. Aspen suckers are preferred by cattle over Douglasfir seedlings (Smith et al., 1972). Wildlife and domestic cattle grazing decrease aspen green biomass, sucker density and height, and ultimately cause sucker mortality (Smith et al., 1972; Singer, 1996).

Douglas-fir is less palatable than aspen, especially in its seedling stage when it is most vulnerable to grazing. Grazing results in a positive net effect for Douglas-fir growth by significantly decreasing herbaceous species, although it causes considerable damage to Douglas-fir through biomass removal and trampling (Hermann and Lavender, 1965). Herbaceous species compete with Douglas-fir seedlings for soil moisture and inhibit seedling establishment (Hermann and Lavender, 1965). We studied the separate response of each tree species to livestock grazing. We explored whether inhibition and facilitation effects of livestock herbivory on tree encroachment differed between aspen and Douglas-fir.

\section{Methods}

\subsection{Study site}

A single, $15 \mathrm{~km}$ long lower forest-grassland ecotone was studied in the Centennial Valley in southwestern Montana in the summer of 2003 (Fig. 1). The Centennial Valley runs east-west at approximately $2100 \mathrm{~m}$ of elevation and experiences extreme continental climate with cold winters and hot, dry summers. The lower forest-grassland ecotone is on the northerly aspect of the Centennial Mountain Range on the south side of the valley. This ecotone runs through the Red Rock Lakes Wildlife Refuge and adjacent private lands, which are currently undeveloped and predominantly used for livestock grazing (Fig. 1). The vegetation community type along the ecotone is Douglas-fir-aspen with structurally simple understory vegetation of $64 \%$ graminoids, $35 \%$ forbs and $1 \%$ shrub. Common graminoids include Agropyron cristatum, Calamagrostis rubescens, Elymus glaucus and Carex geyeri. Common forbs are Fragaria vesca, Geranium viscosissimum, Thalictrum fendleri, and Osmorhiza chilensis. Rosa woodsii and Berberis repens are common shrubs (Mueggler, 1988). Fire was suppressed historically in the valley.

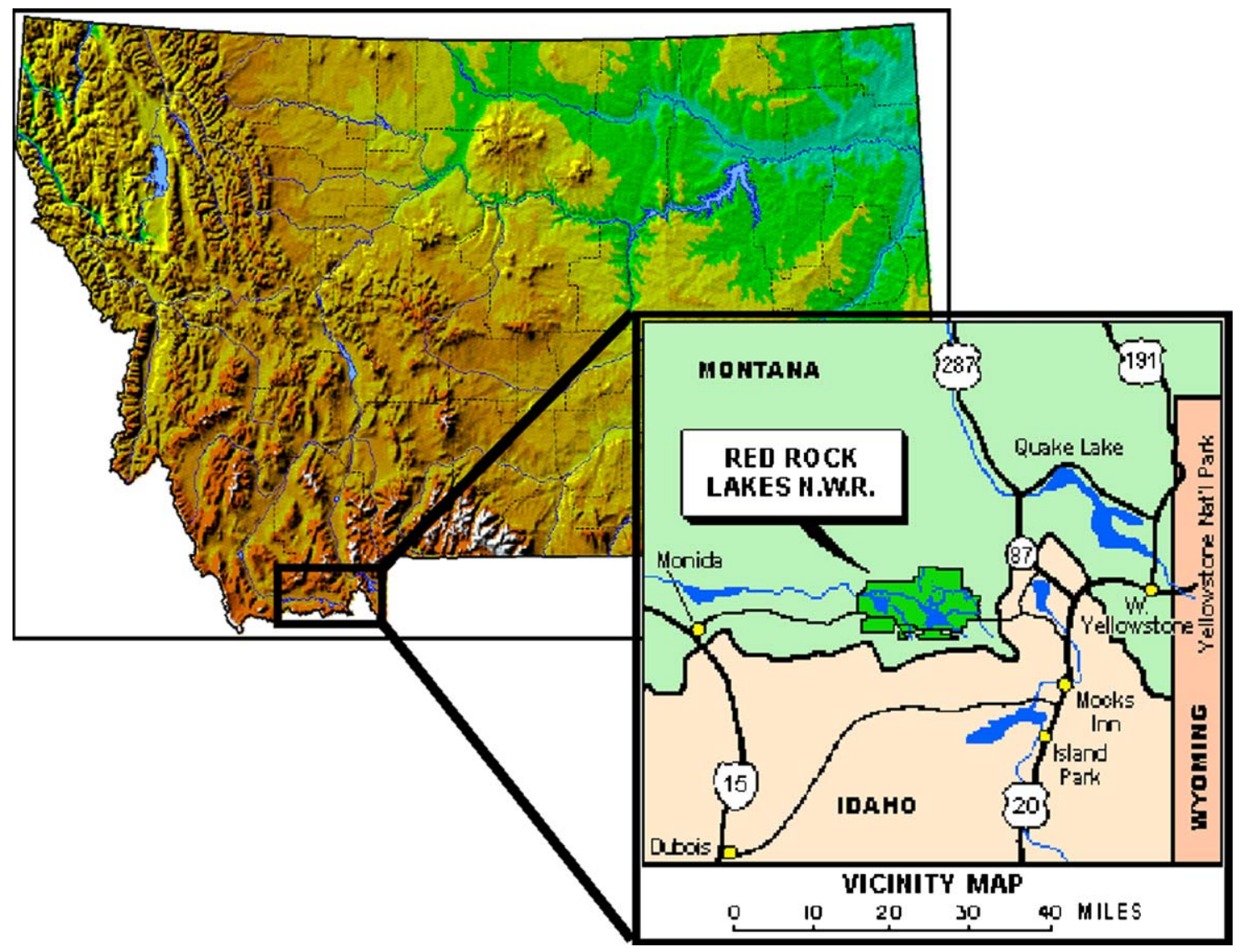

Fig. 1. Study site location. The Centennial Valley is in southwestern Montana. Reference maps are from http://nris.mt.gov/gis/gisdatalib/mtmaps.aspx and http:// redrocks.fws.gov. 
There has been no fire in the valley over the last 130 years except the late summer of 2003 after our field work was completed.

We selected five contiguous sites along the ecotone to study the effects of differing grazing pressure on the lower forestgrassland ecotone shift during the 20th century. The valley has been grazed by domestic livestock since the mid-1800s. Early homesteaders used this area for year-around grazing. The selected five sites have primarily been used as summer pasture for cattle over the last 50-80 years. These sites were carefully selected to represent five different grazing regimes and, at the same time, to minimize differences in physiographic and climatic variables. The fives sites provided a gradient of grazing pressure with each site representing one level of grazing pressure. Interviews with the current land-owners and reviews of the grazing records revealed that the current grazing regime at each site has remained the same over the last 35-40 years. Prior to 1965, however, a majority of the five sites were grazed much more heavily (Brenneman, 2003; Huntsman, 2004). Grazing pressure at that time also varied among sites such that the historic grazing levels provided another gradient of grazing pressure. A combination of the two provided a third gradient with a broader range of grazing pressure. We, therefore, had three different gradients of cattle grazing pressure: (1) a current gradient of five lower levels of grazing pressure; (2) a historic gradient of five higher levels of grazing pressure; (3) a gradient across all 10 levels of grazing pressure. Our gradients of grazing pressure were constructed based on long-term observational data of stocking rates at the five sites of known grazing allotment sizes which remained consistent throughout the entire study period. The grazing pressure at the five sites over the recent decades were estimated based on reviews of the historical and current stocking rates in grazing records, while the grazing pressure in the earlier decades were estimated based on interview information from land owners regarding stocking rates. We believe the interview information to be relatively accurate because the sites have not changed ownership and most were family-owned ranches throughout the 20th Century. The historic and current grazing regimes lasted for 23 years (1942-1965) and 37 years (1965-2002), respectively. The third gradient of grazing pressure included all 10 grazing levels from these two different time periods covering 60 years from 1942 to 2002. This third gradient faced the limitations of observational studies in that there were potential temporal differences between the two time periods in factors that influence tree establishment such as climate variability, wildlife population, and changes in vegetation community dynamics. We were unable to control such factors due to the temporal and spatial extent of our study.

The long-term averages of grazing pressure were estimated and ranked by calculating the level of use (stocking rates) in animal unit months per hectare (AUM/ha). The current gradient of grazing pressure ranged from grazing level 1, the lowest level $(\mathrm{AUM} / \mathrm{ha}=0)$, to grazing level 5, the highest level $(\mathrm{AUM} / \mathrm{ha}=1)$ (Table 1). The historic gradient of grazing pressure also ranged from grazing level $1(\mathrm{AUM} / \mathrm{ha}=0.12)$ to grazing level 5 (AUM/ ha $=2$ ) $($ Table 1$)$. The third gradient ranged from the minimum grazing level from the two smaller gradients, grazing level 1, to the maximum grazing level of the two smaller gradients, grazing level 10. This gradient does not combine the two smaller gradients sequentially, and the order of the grazing levels thus changes from the smaller gradients to the broader gradient (we herein label the current grazing levels along the third gradient with asterisks to distinguish the two time periods). Information from interviews with the Centennial Valley residents and land owners indicate no substantial difference in wildlife use among different land ownership throughout the valley (Huntsman, 2004), although elk population has increased substantially throughout the valley over the last several decades (Brannon, 2005).

\subsection{Field methods and airphoto interpretation}

A total of 106 rectangular plots were established along the ecotone with 20-25 plots at each site. Plot numbers at the five sites were determined based on a statistical power test which indicated that 20 plots were required at each site. Plots were located at fixed intervals within each site (25-150 m depending on the length of ecotone at each site) with their long axis perpendicular to the ecotone. All plots were $10 \mathrm{~m}$ wide with varied lengths of 20-366 m depending on the width of the ecotone, although most plots were $80-100 \mathrm{~m}$ long. The width of the ecotone was determined by the definition of ecotone used in this study: a transition zone between $80 \%$ adult tree canopy cover in the forest and $100 \%$ herbaceous cover in the grassland. The forest end of each plot was positioned at $80 \%$ tree canopy cover, which was ocularly estimated, to represent full canopy forest and included mature trees $>60$ years old based on tree size. Each plot extended from the full canopy forest into the adjacent grassland. The grassland end was positioned at $100 \%$ herbaceous cover and included the farthest out tree seedling or sucker. All adult trees within each plot were identified to the species level, mapped, and cored at $30 \mathrm{~cm}$ above ground with an increment borer to estimate age. Distance of each tree from the forest end of each plot was measured to correlate age estimate and distance of each tree from the forest end of the plots. Percent tree canopy cover was ocularly estimated within each plot. Juveniles of both species, i.e., all seedlings, saplings, and suckers $<2 \mathrm{~m}$ in height and/or $<8 \mathrm{~cm}$ in diameter at coring height, are hereafter referred to as "saplings". All plots were divided into $5 \mathrm{~m} \times 5 \mathrm{~m}$ quadrats. All live saplings were counted and mapped, by species, in the $5 \mathrm{~m} \times 5 \mathrm{~m}$ quadrats within each plot. Additional field data included slope and aspect measurements at each plot.

To corroborate our dendrochronological data, we used two sets of 1:15,000 scale black and white aerial photographs: one set from 1942 and one set from 1999. The 106 plots observed in the field were located on both sets of aerial photographs as precisely as possible. An additional 43 plots (with no ground truth) were also located randomly along the ecotone on both aerial photographs to increase our sample size to 149 plots (3234 plots at each site). These sample sizes were determined based on a statistical power test, which used preliminary data from our aerial photograph analysis. A point intercept method 
was used to detect changes in both the tree density along the ecotone and the forest-grassland boundary location (Kadmon and Harari-Kremer, 1999; Brown, 2003). The point intercept method used grids of points on transparent sheets that were placed over the aerial photographs. We used the same definition of lower forest-grassland ecotone in this analysis. The forest end of each grid, therefore, was placed at $80 \%$ tree canopy cover. The grassland end of each grid was positioned at $100 \%$ herbaceous cover and included the farthest out visible tree or sapling. The number of points within each grid that hit a tree canopy was counted to detect changes in tree density. The total number of rows in each grid that hit a tree canopy was counted to detect changes in the forest-grassland boundary location. Ocular field estimate of tree percent canopy cover in each plot was used to corroborate the aerial photograph interpretation of tree canopy cover. We also estimated current and historic tree density (number of trees per hectare) within the ecotone at all sites to corroborate the aerial photograph interpretation of tree density changes. This estimate was based on the dendrochronological data and the plot size measurements from each site. It did not include sapling data.

\subsection{Tree-age estimate}

We cored 2185 trees and processed and dated the core samples using standard dendrochronological methods (Stokes and Smiley, 1968) (Table 2). A total of 331 aspen samples and 1628 Douglas-fir samples were dated successfully. A total of 194 aspen samples and 85 Douglas-fir samples were eliminated from the analysis because of rotten wood and branch scars. A total of 10,168 saplings were counted. Sapling-age estimate was based on the age distribution of 30 aspen saplings and 30 Douglas-fir saplings which were destructively sampled at the base of the stem. Douglas-fir saplings ranged from 11 to 32 years old and aspen saplings ranged from 3 to 10 years old. We built a regression model using the sapling-age estimate to correlate age and height. Based on this regression model $\left(R^{2}\right.$ of 0.27 and a $p$-value of 0.002$), 29$ years were added to the tree ring count of Douglas-fir samples to adjust for the coring height ( $30 \mathrm{~cm}$ above ground). No additional rings were added to the ring count of aspen samples, because our regression model produced a low coefficient of determination (0.02) and a large $p$-value (0.46). DeByle and Winokur (1985) indicate that aspen stems reach $1.5 \mathrm{~m}$ in $2-5$ years, but some can reach $1.5 \mathrm{~m}$ height in the first year. Romme et al. (1995) indicate that unsuppressed and unbrowsed suckers can grow up to $1 \mathrm{~m}$ a year making it

Table 2

Number of trees sampled for age structure analysis

\begin{tabular}{lrcr}
\hline Sites & No. of aspen samples & No. of Douglas-fir samples & Total \\
\hline 1 & 95 & 444 & 539 \\
2 & 151 & 489 & 640 \\
3 & 82 & 202 & 284 \\
4 & 92 & 312 & 404 \\
5 & 105 & 190 & 295 \\
Total & 525 & 1637 & 2162 \\
\hline
\end{tabular}

unnecessary to adjust ages for coring height. All aspen saplings observed at our study sites showed rapid early growth. Suppressed radial growth and lateral stem dominance due to heavy browsing were not observed at any of the sites.

\subsection{Data analysis}

We first determined whether there had been ecotone shift and tree density increase during the study period. We constructed a tree-age distribution for each site, by species, at a decadal scale to determine if new trees established during the study period within the ecotone. Once it was determined that new trees had successfully established during the study period, we were interested in exploring if a relationship existed between tree age and tree location within the ecotone. If the ecotone was shifting, we would expect a process of new tree establishment closer to the grassland. We were interested in describing this particular process, although many ecological processes could impact tree regeneration and mortality patterns along the ecotone and make this process difficult to distinguish. After we tested for spatial autocorrelation in the residuals of a tree age and tree location model and found no pattern in our variogram, we examined adult tree-age estimates with the distance of trees from the forest end of the plots and used a regression model to describe the relationship between tree age and distance. Tree age was the response variable and tree distance was the predictor variable. Tree distance from the forest end of each plot was expressed in percent to standardize the tree distance data because plot lengths varied. The regression model also included the five sites as an indicator variable, and interaction terms of tree distance and sites, to reduce the error effects caused by site differences and to test for differences among sites. The interaction terms were not statistically significant and were, therefore, excluded from the final model. This analysis included the adult trees only.

To corroborate the dendrochronological data, we analyzed our aerial photograph data using paired $t$-tests. The number of points and the total number of rows within the grids that hit tree canopy were compared separately through this test between the two dates. Increase in the total number of rows that hit tree canopy would indicate ecotone shift, whereas increase in the number of points (expressed in \%) within the same number of rows would indicate tree density increase.

We then examined grazing effects on ecotone shift. We estimated the number of new trees established each year (expressed in percent) and the number of saplings (expressed as sapling to adult ratio) over the study period established in the last 32 years (between 1970 and 2002) under each grazing regime at each site. We performed one-way ANOVA tests to determine grazing effects across each gradient on each tree species. Grazing levels (indicator variable) were the predictor variable and the number of new trees and saplings established was the response variable. We also constructed a regression model of all 10 grazing levels (AUM/ha) and tree establishment to describe the overall relationship between grazing pressure and ecotone shift. We built separate regression models for the two tree species. The number of new trees and saplings established were the response 
variable and the grazing levels (AUM/ha) and a squared term were the predictor variables. The squared term was used in the model, because a statistically significant squared term might indicate a possibility of a curvilinear relationship instead of a linear relationship. The squared term was not statistically significant for the Douglas-fir regression. We, therefore, constructed another regression model for Douglas-fir which included only the grazing levels as a predictor variable.

To address the third question, we examined the differential effects of grazing on different tree species through a two-way ANOVA test with grazing levels and tree species as predictor variables. We also performed a four-way ANOVA test to examine the effects of grazing levels, difference in tree species, and topographic aspect and slope on tree establishment. This test simultaneously determined the interaction between grazing levels and difference in tree species, the interaction between grazing levels and aspect, the interaction between grazing levels and slope, the interaction between difference in tree species and aspect, the interaction between difference in tree
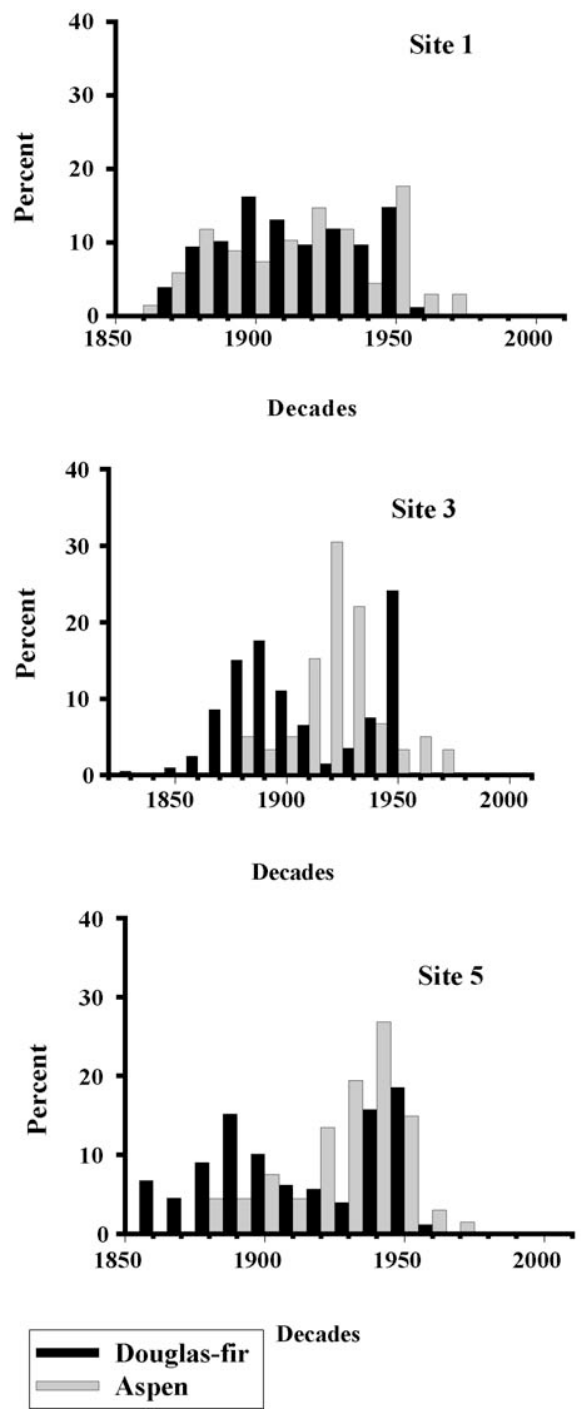

species and slope, and the interaction between slope and aspect. Tukey's multiple comparison was used for all ANOVA tests with a significant predictor variable. This test used a pair-wise comparison with all pairs and determined where significant differences occurred.

\section{Results}

\subsection{Forest-grassland ecotone shift}

Tree-age distribution was constructed at a decadal scale and indicated that new Douglas-fir and aspen trees had successfully established within the ecotone at all five sites in the last 60 years (Fig. 2). Up to $45 \%$ of the adult Douglas-fir trees were new trees that established since 1942 (Table 3). The tree-age distribution indicated that a few new Douglas-fir trees established after the decade of 1970. This can be partially explained by the saplingage estimate, which indicated that Douglas-fir sapling age ranged from 11 to 32 years. This range indicated that Douglas-fir that
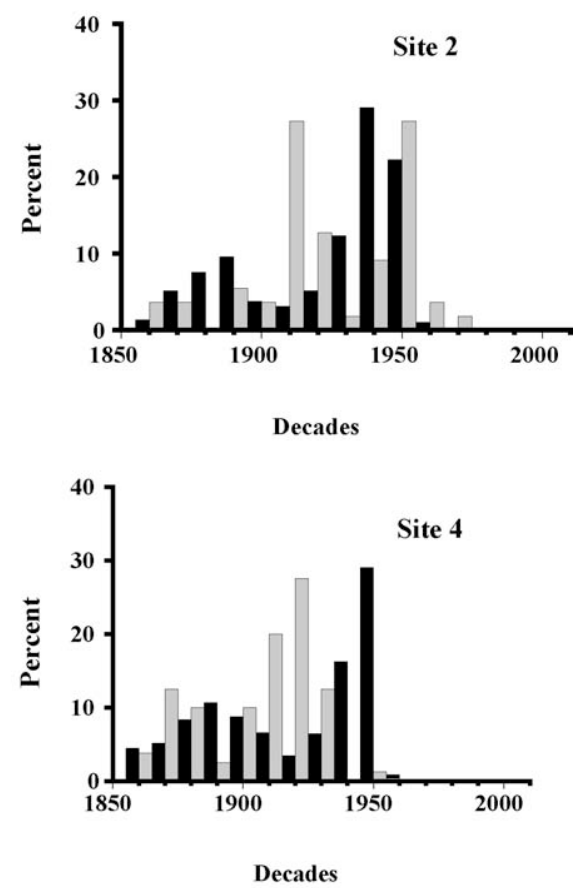

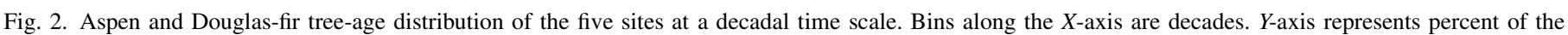

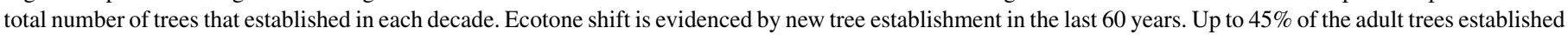
since 1942. 
Table 3

Evidence of ecotone shift at all sites

\begin{tabular}{|c|c|c|c|c|c|}
\hline Sites & $\begin{array}{l}\text { Current grazing } \\
\text { level }\end{array}$ & $\begin{array}{l}\text { Percent of new Douglas-fir } \\
\text { established since } 1942\end{array}$ & $\begin{array}{l}\text { Percent of new aspen } \\
\text { established since } 1942\end{array}$ & $\begin{array}{l}\text { Distance of saplings established in the } \\
\text { adjacent grassland from adult trees (m) }\end{array}$ & $\begin{array}{l}\text { Evidence of ecotone } \\
\text { shift (yes/no) }\end{array}$ \\
\hline 1 & Level $1^{*}$ & 21 & 19 & 64 & Yes \\
\hline 2 & Level $2^{*}$ & 45 & 25 & 58 & Yes \\
\hline 3 & Level $3^{*}$ & 30 & 11 & 44 & Yes \\
\hline 4 & Level $4^{*}$ & 33 & 27 & 43 & Yes \\
\hline 5 & Level $5^{*}$ & 42 & 0.7 & 112 & Yes \\
\hline
\end{tabular}

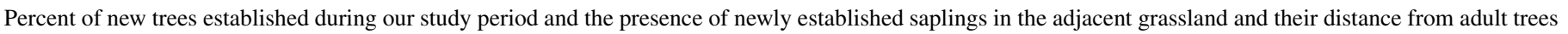
were used to assess the evidence of ecotone shift and the aerial photograph interpretation.

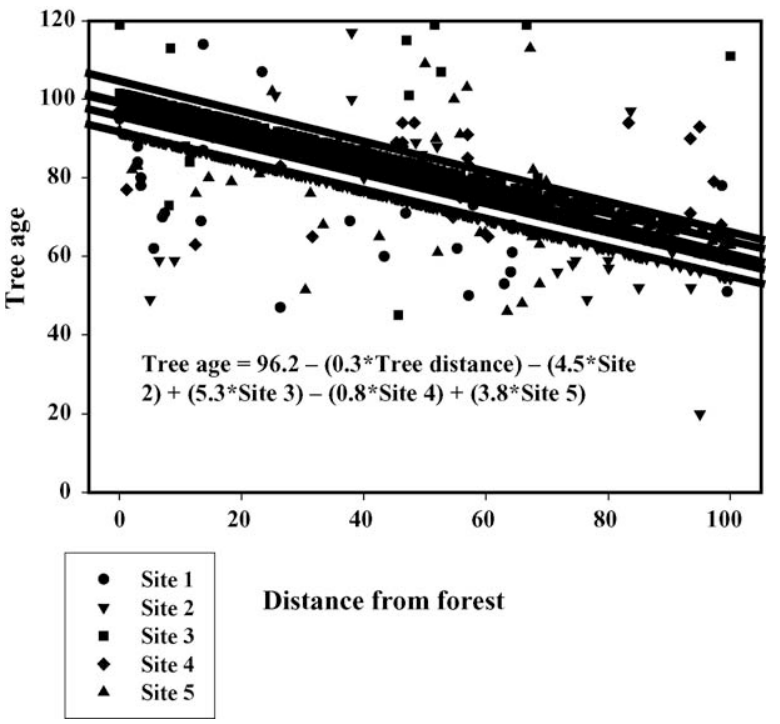

Fig. 3. Tree age and tree distance relationship at all sites. The estimate of tree age expressed in years is on $Y$-axis. The distance of trees from full canopy forest is on the $X$-axis and is expressed in percent. A single regression model was constructed with a separate indicator variable for each site. Tree distance was a significant predictor variable and tree age showed a trend of decrease with increasing distance at all sites. Coefficients for Sites 2, 3, and 5 were significantly different $(p$-value $<0.05)$ compared to Site 1 . Site 4 was not significantly different compared to Site $1(p$-value $=0.87)$.

established since 1970 were likely classified as saplings and were not included in the adult tree-age distribution. The additional 1244 Douglas-fir stems counted as saplings provided further evidence of new tree establishment in the last 60 years. New aspen trees established in the last 60 years made up 1-27\% of the adult aspen population (Table 3 ). The sapling-age estimate indicated that aspen sapling age ranged from 3 to 10 years. Aspen stems that established since 1992 were likely classified as saplings and were not included in the adult tree-age distribution. The additional 8924 aspen stems counted as saplings were established in the last 10 years and provided additional evidence of successful aspen establishment.

We then analyzed the estimated adult tree age with tree distance from the forest end of the plots to describe the process of ecotone shift. We constructed a regression model (Fig. 3), which produced significant $p$-values for the model $(<0.001)$ and the predictor variables of distance $(<0.001)$ and site $(<0.001)$. Tree age showed a trend of decrease with increasing distance from the forest end of the plots. This might indicate that the process of ecotone shift into the adjacent grassland was occurring at all sites. The model produced a low $R^{2}$ of 0.14 . We expected a low coefficient of determination in describing this process because many other ecological processes influence regeneration patterns along the ecotone and make this process difficult to discern. The coefficients for Sites 2, 3, and 5 were significantly different compared to Site 1 and the coefficient for Site 4 was not significantly different than Site 1.

To corroborate the dendrochronological data, we compared our aerial photograph data between the two dates (Table 4). The aerial photograph comparison showed $15-96 \%$ increase in the total number of rows in the grids that hit tree canopy indicating a shift in the ecotone location towards the grassland. Sites 1-3 had a statistically significant increase in the total number of rows that hit tree canopy. The aerial photograph comparison

Table 4

Aerial photograph comparison and corroboration of ecotone tree canopy cover

\begin{tabular}{lllcccc}
\hline Sites & $\begin{array}{l}\text { 1942 points in } \\
\text { airphoto (\%) }\end{array}$ & $\begin{array}{l}\text { 1999 points in } \\
\text { airphoto (\%) }\end{array}$ & $\begin{array}{l}\text { Total no. of rows } \\
\text { in 1942 airphoto }\end{array}$ & $\begin{array}{l}\text { Total no. of rows } \\
\text { in 1999 airphoto }\end{array}$ & $\begin{array}{l}\text { Tree density estimate } \\
\text { (tree/ha) in 1942 }\end{array}$ & $\begin{array}{l}\text { Tree density estimate } \\
\text { (tree/ha) in 1999 }\end{array}$ \\
\hline $1^{*}$ & 59 & 68 & 9 & 13 & 70 & 320 \\
$2^{*}$ & 51 & 66 & 7 & 14 & 80 & 220 \\
$3^{*}$ & 61 & 65 & 10 & 14 & 80 & 310 \\
4 & 54 & 37 & 9 & 10 & 110 & 330 \\
5 & 53 & 56 & 8 & 10 & 10 & 330 \\
\hline
\end{tabular}

Sites with significant increases in tree canopy cover between the two dates are marked with asterisks $(*)$. The average number of points within the grids that hit a tree canopy (expressed in \%) was counted to detect changes in tree density at each site. The total number of rows in the grids that hit a tree canopy was counted to detect changes in the forest-grassland boundary location at each site. The aerial photograph interpretation was corroborated with 1942 and 1999 tree density estimates based on dendrochronological data. 
also showed an increase in the number of rows that hit tree canopy cover at Site 5 , but this increase was not statistically significant. Site 4 had decreased tree cover due to road construction and associated tree cutting. The aerial photograph point intercept comparison indicated $2-10 \%$ increase in tree percent canopy cover along the ecotone. The $t$-test showed that Sites 1-3 had a statistically significant increase in tree cover between the two dates ( $p$-value of $0.00001,0.0001,0.003$ ) indicating a statistically significant increase in tree density. An increase in tree cover was also observed at Site 5, but this increase was not statistically significant ( $p$-value of 0.167 ). No decrease in tree canopy cover was observed except at Site 4 where a decrease was observed again due to a road construction and associated tree cutting within the ecotone. To corroborate the aerial photograph interpretation of tree cover changes, we estimated 1942 and 1999 tree density (number of trees per
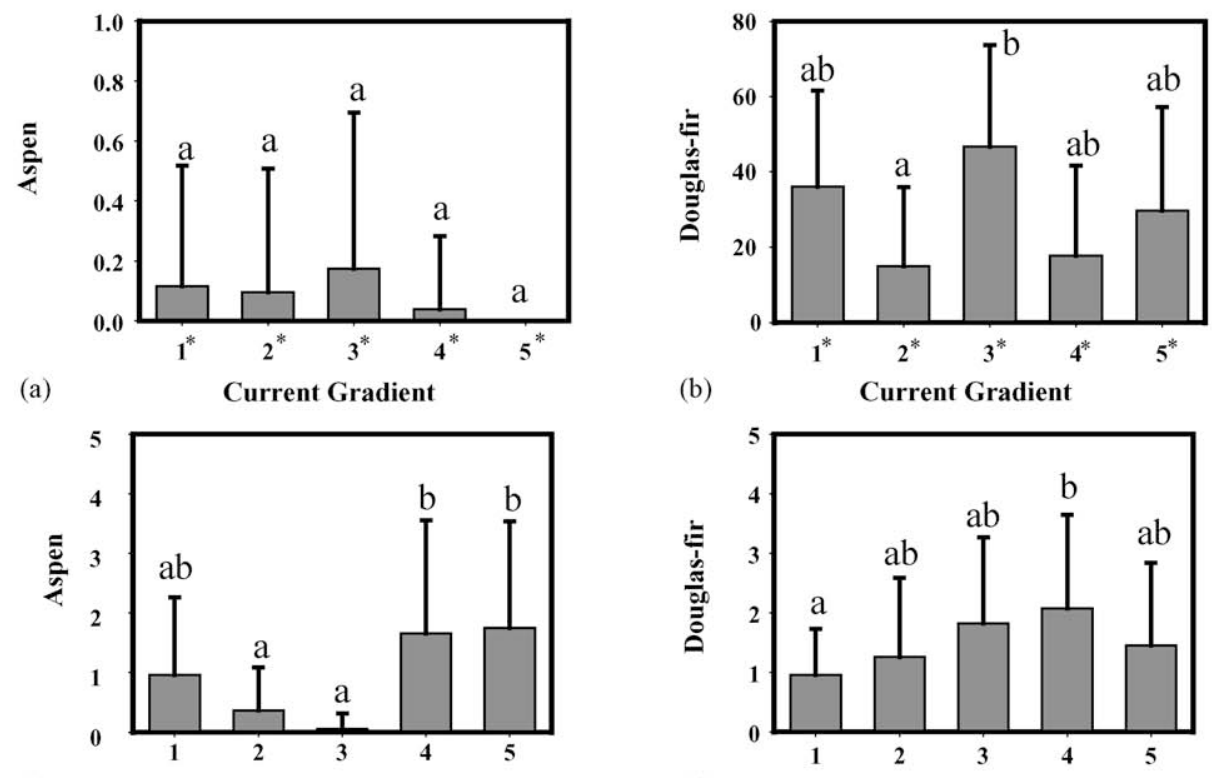

(c)

Historic Gradient

(d)
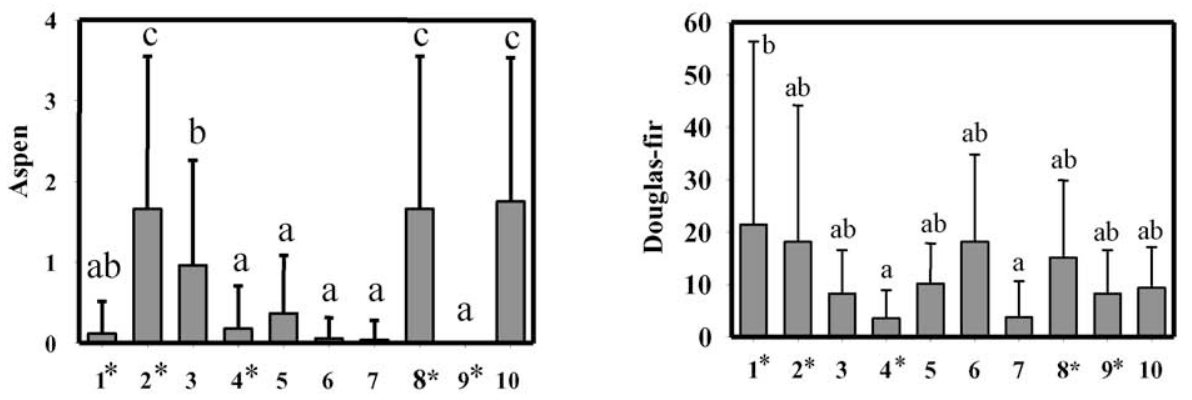

(e) Gradient Across Ten Levels

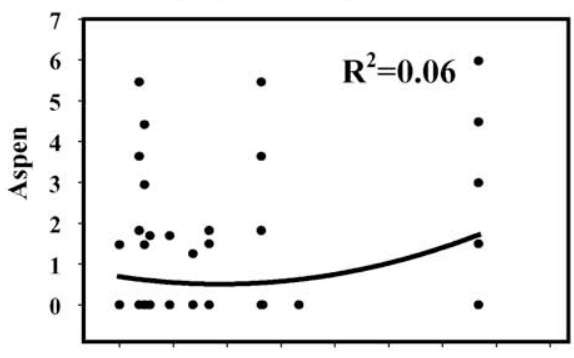

$\begin{array}{lllllllll}0.0 & 0.3 & 0.6 & 0.9 & 1.2 & 1.5 & 1.8 & 2.1 & 2.4\end{array}$

(g)

Grazing Levels (AUM/ha)

\section{(f)}

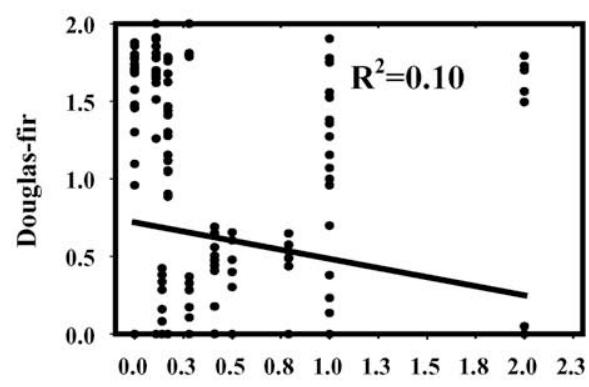

(h)

\section{Grazing Levels (AUM/ha)}

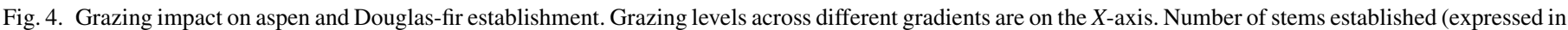

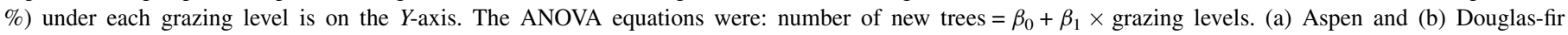

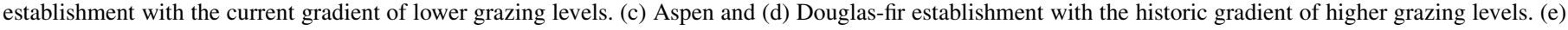

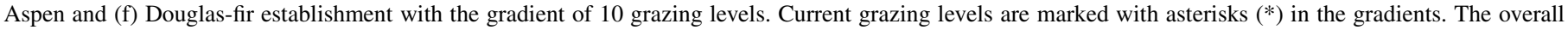

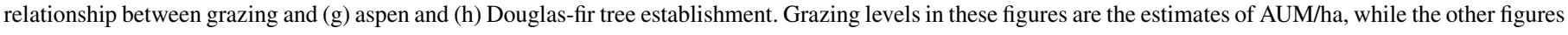
have categories for grazing levels. 
hectare) at each site based on the dendrochronological data (Table 4). These estimates supported the trends observed in the aerial photograph comparison.

\subsection{Grazing effects on ecotone shift}

We performed a two-way ANOVA test to determine the effects of grazing pressure and the difference in tree species on tree establishment. The tree species and the interaction term of grazing levels and tree species were significant predictor variables ( $p$-value 0.001 and 0.003 , respectively). This indicated that each tree species responded to different grazing levels differently and, within each species, the response varied due to the grazing levels. We analyzed the separate responses of aspen and Douglas-fir to grazing across all gradients with ANOVA and Tukey's multiple comparison tests.

We first analyzed the number of trees established in the last 37 years with the current grazing levels. The number of aspen trees established did not differ significantly among the current grazing levels ( $p$-value of 0.09) (Fig. 4(a)). Current grazing level 3 had a significantly greater number of Douglas-fir trees established than current grazing level 2 ( $p$-value $<0.001$ ) (Fig. 4(b)). There were no other significant differences in tree establishment along this gradient. There was no apparent trend of linear increase or decrease in aspen and Douglas-fir establishment with increasing grazing pressure along this gradient.

We then analyzed the number of trees established between 1942 and 1965 with the historic grazing levels. Historic grazing levels 4 and 5 had significantly greater numbers of aspen than historic grazing levels 2 and 3 ( $p$-value $<0.001$ ) (Fig. 4(c)). Historic grazing level 4 had significantly greater Douglas-fir establishment compared to historic grazing level 1 ( $p$-value of 0.03) (Fig. 4(d)). There were no other significant differences in tree establishment along this gradient. There was no apparent trend of linear increase or decrease in aspen and Douglas-fir establishment with increasing grazing pressure along this gradient.

Next we analyzed the number of trees established with all 10 grazing levels (Fig. 4(e) and (f)). Grazing levels $2^{*}, 8^{*}$, and 10 had significantly greater aspen establishment than all other grazing levels ( $p$-value $<0.001$ ) (Fig. 4(e)). Grazing level 3 had significantly greater aspen establishment than grazing levels $4^{*}, 5-7$ and $9^{*}$ ( $p$-value $\left.<0.001\right)$. There were no other significant differences in aspen establishment along this gradient. Grazing level 1 had significantly greater Douglasfir establishment compared to grazing levels $4^{*}$ and 7 ( $p$-value of 0.002) (Fig. 4(f)). There were no other significant differences in Douglas-fir establishment. There was no apparent trend of linear increase or decrease in aspen and Douglas-fir establishment with increasing grazing pressure along this gradient.

We also constructed a regression model of all 10 grazing levels (AUM/ha) and tree establishment to describe the overall relationship between livestock herbivory and tree establishment (Fig. 4(g) and (h)). The regression of all 10 grazing levels, with a squared term, and aspen establishment produced a significant $p$-value of $<0.001$ for the model, but a low $R^{2}$ of
0.06. Grazing levels and the squared term were significant predictor variables ( $p$-value of 0.01 for both). The statistically significant squared term might indicate a possibility of a curvilinear relationship between aspen establishment and grazing levels (Fig. 4(g)). The regression model of all 10 grazing levels, with a squared term, and Douglas-fir establishment also produced a low $R^{2}$ of 0.01 . The squared term was not significant as a predictor variable in this model ( $p$-value of $0.17)$. The final regression model thus included only the grazing levels as a predictor variable. This new model with a single predictor variable produced a low $R^{2}$ of 0.10 and a $p$ value of 0.07 for the predictor variable and a $p$-value of $<0.0001$ for the model. Douglas-fir establishment showed a trend of decrease with increasing grazing pressure along this gradient (Fig. 4(h).

\subsection{Effects of abiotic factors on ecotone shift}

A four-way ANOVA test was performed to determine the effects of grazing levels, difference in tree species, topographic aspect, and slope. Topographic slope and aspect were not significant predictor variables ( $p$-value of 0.12 and 0.62 , respectively). None of the interaction terms was significant. At a coarse scale, our entire ecotone was found on a north-tending aspect with little variation in aspect. Aspects in our study sites ranged from $260^{\circ}$ (northwest) through north to $40^{\circ}$ (northeast). The slope also varied little ranging from $5^{\circ}$ to $20^{\circ}$.

\section{Discussion}

\subsection{Forest-grassland ecotone shift}

Our results indicated that both types of ecotone change occurred in the Centennial Valley during the study period: a shift in ecotone location towards the adjacent grassland and an increase in tree density within the same forest boundary location. These changes were evidenced by our combined results from three different sources. First, the tree-age distribution indicated that up to almost half of the adult trees within the ecotone were new trees that established during the study period. Furthermore, the ecotone tree-age distribution showed two interesting patterns. The Douglas-fir tree-age distribution was similar to that of newly established, young Douglas-fir forest stands and was dominated by a much younger range of tree ages compared to typical multi-aged forest stands (Franklin and Hemstrom, 1981). Our aspen treeage distribution showed successful regeneration throughout the 20th Century in contrast to aspen tree-age distribution patterns from other studies in the Greater Yellowstone Ecosystem that indicate decreased aspen cover in this region due to lack of 20th century regeneration (Ripple and Larsen, 2000).

Second, the aerial photograph comparison indicated a statistically significant increase in the total number of rows that hit tree canopy at three of the sites. This indicated that new trees had established further in the adjacent grassland over the study period which would result in a shift in the forest-grassland boundary location. The aerial photograph comparison also 
indicated that the total number of points that hit tree canopy increased during the study period possibly resulting in tree density increase along the ecotone. This possible increase in tree density was also indicated by our estimates of current and historic tree density at all sites. Other ecotone change studies have also shown that both tree density increase and a shift in ecotone location can occur at the same time (Arno and Gruell, 1986; Dando and Hansen, 1990). Our results are consistent with the conclusions of such studies.

Third, our regression results of tree age and tree distance might indicate that tree age decreased with increasing distance from full canopy forest towards the adjacent grassland, although the coefficient of determination was low. This trend might indicate that the younger trees were found closer to the grassland end of the ecotone, while older trees were found at the forest end of the ecotone. This trend provided an evidence of shifting forest-grassland ecotones in the Centennial Valley. The pattern in our regression model also supports the trends that we observed in our aerial photograph comparison results.

\subsection{Tree species response to grazing}

Interesting patterns were observed when the responses of aspen and Douglas-fir to grazing were examined. First, the difference in tree species response to grazing was statistically significant indicating that aspen and Douglas-fir establishment responded to grazing differently. This is consistent with the literature suggesting that aspen and Douglas-fir are different in their palatability and, therefore, might be impacted by grazing differently. Second, neither species showed a consistent pattern of decrease or increase with increasing grazing pressure when analyzed with different gradients at decadal time scales. The pattern of increase and decrease in tree establishment with increasing grazing levels was not consistent even among different grazing levels within a single gradient. These results showed that tree response to grazing was complex and varied across different grazing levels and different grazing gradients. These results might also provide a potential explanation for variable results of tree response to grazing found in the current literature.

\subsection{Grazing effects on ecotone shift}

Our results indicated that livestock herbivory is a complex variable. Both aspen and Douglas-fir showed statistically significantly different rates of establishment associated with different levels of grazing pressure along different grazing gradients. However, we did not always find a simple linear increase or a simple linear decrease in tree encroachment with increasing grazing pressure. At decadal time scales, simple linear trends of inhibition effects and facilitation effects did not appear to hold across varying gradients of grazing levels and two different tree species. Only one of the eight grazing models, Douglas-fir establishment and grazing regression model, indicated the possibility of a linear decrease in tree establishment with increasing grazing pressure. Indeed, the aspen establishment and grazing regression results might point to the possibility of a curvilinear relationship between tree establishment and increasing grazing pressure.

Different aspects of our ANOVA test results, however, supported both of the two seemingly conflicting conclusions from previous studies. Some of our results were consistent with the conclusions of grazing studies that grazing can have inhibition effects on tree establishment (Carmel and Kadmon, 1999; Bartolome et al., 2000). Other results from this study were also consistent with the results of other grazing studies that grazing can have facilitation effects on tree establishment (Dando and Hansen, 1990; Archer, 1999). Furthermore, some of our results did not show significant effects of grazing disturbance on tree establishment. This was consistent with the conclusions of a recent elk browsing study that found no significant effect of different browsing levels on tree establishment (Barnett and Stohlgren, 2001). Taken together, our results showed that grazing was a complex variable with no consistent, simple linear effects on tree encroachment. These results suggested that no consistent conclusions could be made regarding grazing effects on tree establishment across broad ranges of grazing intensity at decadal time scales.

It is possible, however, that decadal scale averages in grazing pressure blurs the grazing effects and makes the relationship difficult to detect. Another estimate of grazing pressure or a different component of the relationship might better describe the trend, if a trend exists at a decadal scale. Further, interactive effects of multiple factors might make the relationship difficult to detect, although we made an effort to ensure statistical power in the variables measured in this study. Many other potential factors that influence tree regeneration patterns were not controlled in this study due to the spatial and temporal extent of the study. Future studies might need better controlled experiments to eliminate the effects of multiple other factors, such as climate variability and wildlife grazing, and to identify the processes of tree response to livestock grazing only.

\section{Conclusion}

This study showed that the lower forest-grassland ecotone in the Centennial Valley is shifting into the adjacent grassland and tree density is increasing along the forest boundary. At decadal time scales, livestock herbivory effect on tree encroachment was not always simple and linear with a consistent decrease or increase in tree establishment. Livestock herbivory was a complex variable. Our results and the conclusions in the current literature demonstrate varying effects of grazing pressure on woody species expansion. These patterns demonstrate the need for future research with process-based experiments focused on grazing effects and tree response, while eliminating the effects of other potential factors to enhance our current understanding of ecotone dynamics under grazing effects. We suggest that the way forward needs to use a process-based approach to devise strategies for observing and quantifying multiple interacting processes of inhibition and facilitation effects. 


\section{References}

Alverson, W.S., Waller, D.W., Solheim, S.L., 1988. Forests too deer: edge effects in northern Wisconsin. Conserv. Biol. 2, 348-358.

Archer, S., 1999. Woody plant encroachment into southwestern grasslands and savannas: rates, patterns and proximate causes. In: Vavra, M., Laylock, W., Pieper, R.D. (Eds.), Ecological Implications of Livestock Herbivory in the West. Society for Range Management, Denver, pp. 13-69.

Arno, S.F., Gruell, G.E., 1986. Douglas-fir encroachment into mountain grasslands in southwestern Montana. J. Range Manage. 39, 272-275.

Bachelet, D., Lenihan, J.M., Daly, C., Neilson, R.P., 2000. Interactions between fire, grazing and climate change at Wind Cave National Park, SD. Ecol. Mod. 134, 229-244.

Barnett, D.T., Stohlgren, T.J., 2001. Persistence of aspen regeneration near the National Elk Refuge and Gros Ventre Valley elk feedgrounds of Wyoming. Sustaining aspen in western landscapes.In: Symposium Proceesings RMRSP-18.

Bartolome, J., Franch, J., Plaixats, J., Seligman, N.G., 2000. Grazing alone is not enough to maintain landscape diversity in the Montseny Biosphere Reserve. Agric. Ecosyst. Environ. 77, 267-273.

Brannon, B., 2005. Personal communication. US Department of Fish, Wildlife and Parks.

Brenneman, S., 2003. Personal communication. Dillon, Montana.

Brown, K., 2003. Understanding the role of biophysical setting in aspen persistence. MS Thesis. Montana State University.

Carmel, Y., Kadmon, R., 1999. Effects of grazing and topography on long-term vegetation changes in a Mediterranean ecosystem in Israel. Plant. Ecol. 145, 243-254.

Dando, L.M., Hansen, K.J., 1990. Tree invasion into a range environment near Butte, Montana. Great Plains-Rocky Mount. Geog. J. 18 (1), 65-76.

DeByle, N.V., Winokur, R.P., 1985. Aspen: ecology and management in the Western United States. General Technical Report RM-119. Rocky Mountain Forest and Research Station, Fort Collins, CO.

Franklin, J.F., Hemstrom, M.A., 1981. Aspects of succession in the coniferous forests of the Pacific Northwest. In: West, D.C., Shugart, H.H., Botkin, D.B. (Eds.), Forest Succession: Concepts and Application.

Hermann, R.K., Lavender, D.P., 1965. Douglas-Fir. Silvics Manual, Agriculture Handbook 654, vol. 1. United States Department of Agriculture, Forest Service.

Hill, J.D., Canham, C.D., Wood, D.M., 1995. Patterns and causes of resistance to tree invasion in rights-of-way. Ecol. Appl. 5, 459-470.

Hjalten, J., Danell, K., Ericson, L., 1993. Effects of simulated herbivory and intra-specific competition on the compensatory ability of birches. Ecology $74,1136-1142$.
Huntsman, E., 2004. Personal communication. Centennial Valley.

Kadmon, R., Harari-Kremer, R., 1999. Studying long-term vegetation dynamics using digital processing of historical aerial photographs. Remote Sens. Environ. 68, 164-176.

Kay, E.C., Bartos, D.L., 2000. Ungulate herbivory on Utah aspen: assessment of long-term exclosures. J. Range Manage. 53, 145-153.

Kilpatrick, S., Abendroth, D., 2001. Aspen response to prescribed fire and wild ungulate herbivory. In: Sustaining Aspen in Western Landscapes: Symposium Proceesings RMRS-P-18.

Kupfer, J.A., Cairns, D.M., 1996. The suitability of montane ecotones as indicators of global climatic change. Prog. Phys. Geogr. 20, 253272.

Mather, A., 2000. South-north challenges in global forestry. In: Palo, M., Vananen, H. (Eds.), World Forests from Deforestation to Transition. Kluwer Academic Publishers, Dordrecht.

McInnes, P.F., Naiman, R.J., Pastor, J., Cohen, Y., 1992. Effects of moose browsing on vegetation and litter of the boreal forest, Isle Royle, MI, USA. Ecology 73, 2059-2075.

Mueggler, M., 1988. Aspen community types of the Intermountain Region. General Technical Report INT-250. United States Department of Agriculture. Forest Service. Intermountain Research Station.

Ripple, W.J., Larsen, E.J., 2000. Historic aspen recruitment, elk, and wolves in northern Yellowstone National Park, USA. Biol. Conserv. 95, 361370.

Romme, W.H., Turner, M.G., Wallace, L.L., Walker, J.S., 1995. Aspen, elk, and fire in northern Yellowstone Park. Ecology 76, 2097-2106.

Rooney, T.P., Solheim, S.L., Waller, D.M., 2002. Factors affecting the regeneration of northern white cedar in lowland forests of the Upper Great Lakes Region, USA. For. Ecol. Manage. 163, 119-130.

Rumble, M.A., Pella, T., Sharps, J.C., Carter, A.V., Parrish, B., 1996. Effects of logging slash on aspen regeneration in grazed clear-cuts. Prairie Nat. 28, 199-210.

Singer, F.J., 1996. Effects of grazing by wild ungulates in Yellowstone National Park. Technical Report NPS/NRYELL/NRTR/98-01. United States Department of the Interior, National Park Service, Yellowstone National Park.

Smith, A.D., Lucas, P.L., Baker, C.O., Scotter, G.W., 1972. The effects of deer and domestic livestock on aspen regeneration in Utah, Publication No. 72-1. Utah Division of Wildlife Resources.

Stokes, M.A., Smiley, T.L., 1968. An introduction to Tree-ring Dating. The University of Arizona Press, Tucson.

Tilghman, N.G., 1989. Impacts of white-tailed deer on forest regeneration in Northwestern Pennsylvania. J. Wildl. Manage. 53, 524-531. 